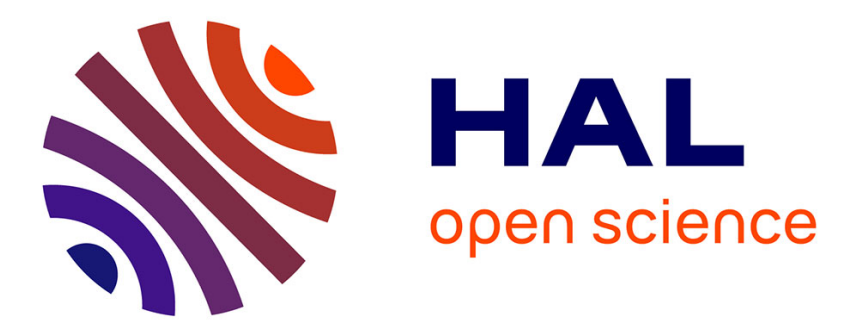

\title{
Blindness, But Not HMHA Anosmia, Predicts Loneliness: A Psychophysical Study
}

Agnieszka Sorokowska, Anna Janczak, Camille Ferdenzi, Nicolas Baldovini, Anna Oleszkiewicz

\section{- To cite this version:}

Agnieszka Sorokowska, Anna Janczak, Camille Ferdenzi, Nicolas Baldovini, Anna Oleszkiewicz. Blindness, But Not HMHA Anosmia, Predicts Loneliness: A Psychophysical Study. Personality and Social Psychology Bulletin, 2021, pp.014616722110343. 10.1177/01461672211034376 . hal-03432461

\section{HAL Id: hal-03432461 https://hal.science/hal-03432461}

Submitted on 17 Nov 2021

HAL is a multi-disciplinary open access archive for the deposit and dissemination of scientific research documents, whether they are published or not. The documents may come from teaching and research institutions in France or abroad, or from public or private research centers.
L'archive ouverte pluridisciplinaire HAL, est destinée au dépôt et à la diffusion de documents scientifiques de niveau recherche, publiés ou non, émanant des établissements d'enseignement et de recherche français ou étrangers, des laboratoires publics ou privés. 


\section{Blindness, But Not HMHA Anosmia, Predicts Loneliness: A Psychophysical Study}

Personality and Social Psychology Bulletin $1-10$

(C) 2021 by the Society for Personality and Social Psychology, Inc Article reuse guidelines: sagepub.com/journals-permissions DOI: $10.1177 / 01461672211034376$ journals.sagepub.com/home/pspb (S)SAGE

\author{
Agnieszka Sorokowska' (iD, Anna Janczak', Camille Ferdenzi², \\ Nicolas Baldovini ${ }^{3}$, and Anna Oleszkiewicz ${ }^{1,4}$
}

\begin{abstract}
Olfactory deficits can play a detrimental role in everyday social functioning. Perception of 3-hydroxy-3-methylhexanoic acid (HMHA) - a body odor component — could also be linked to this research area. However, no study so far has addressed the problem of HMHA perception in the context of the previously reported relationship between olfactory abilities and social difficulties. Here, we tested whether HMHA-specific anosmia predicted loneliness understood both as a cognitive evaluation of social participation and as one's social isolation, and we additionally analyzed the effects and correlates of HMHA perception in relation to sightedness. The study comprised 196 people, of whom 99 were blind. We found that subjects with blindness declared particularly high loneliness, but HMHA anosmia and the interaction of sightedness and HMHA anosmia predicted neither loneliness nor social withdrawal. In addition, HMHA pleasantness was positively associated with social withdrawal of the subjects with blindness and emotional loneliness correlated with HMHA familiarity regardless of sightedness.
\end{abstract}

\title{
Keywords
}

loneliness, olfaction, blindness, body odor, 3-hydroxy-3-methyl-hexanoic acid (HMHA)

Received December 4, 2020; revision accepted June 28, 2021

The sense of smell contributes to social communication (Stevenson, 2010), and perception of body odors seems crucial for this aspect of olfactory functioning. Body odors communicate numerous human characteristics (de Groot et al., 2017), ranging from sex (Lenochova \& Havlicek, 2007), age (Mitro et al., 2012), or health status (Olsson et al., 2014) to emotional state (Chen \& Haviland-Jones, 2011) or personality traits (Sorokowska et al., 2012). Given this multitude of information and apparent importance of this aspect of a human physique, it may be assumed that olfactory sensitivity plays an important role in everyday social functioning. Indeed, studies show that people with anosmia, that is, those without the sense of smell, exhibit a significantly higher level of social insecurity than those with functioning olfaction (Croy et al., 2012, 2013). Olfactory abilities were also found to relate to self-reported loneliness (Desiato et al., 2020; Sivam et al., 2016) and quantity and quality of social relationships for women (Zou et al., 2016), but not men (Boesveldt et al., 2017). However, existing studies do not enable us to determine the causality in the relationship between olfactory sensitivity and interpersonal problems, nor to define the mechanisms that drive this relationship. As can be predicted based on Croy et al.'s (2013) study, access to olfactory information can make social relationships easier and broader, diminishing insecurity and, consequently, facilitating new social and romantic contacts. Furthermore, sensory disorders decrease the control one has over his or her own odor, which may further moderate the self-consciousness (Stefanczyk \& Oleszkiewicz, 2020). As suggested by Desiato et al. (2020), olfactory dysfunctions could affect loneliness also through a mediating effect of depression generated by smell disorders. Nevertheless, the links between olfactory sensitivity and social functioning definitely need to be explored further. For example, it seems extremely interesting whether anosmia to odors emanating from a human body plays a particularly important role in the interpersonal problems and whether the relationship between olfaction and social functioning is equally strong for everyone.

\footnotetext{
'Institute of Psychology, University of Wroclaw, Poland

${ }^{2}$ Lyon Neuroscience Research Center, CNRS UMR5292 - Inserm UI028 Claude Bernard University Lyon I, Bron, France

'Université Côte d'Azur, Nice, France

${ }^{4}$ Smell and Taste Clinic, Technische Universität Dresden, Germany

Corresponding Author:

Anna Oleszkiewicz, Institute of Psychology, University of Wroclaw, PI. Dawida I, Wroclaw 50-527, Poland.

Email: ania.oleszkiewicz@gmail.com
} 
People differ in their olfactory sensitivity (Oleszkiewicz et al., 2020), and variability of responses to odors is observed also for chemical compounds composing body odors. Body odors are also highly diverse as they are subject to genetic (Havlicek \& Roberts, 2009; Roberts et al., 2005; Wallace, 1977), environmental (Fialová et al., 2013, 2016; Lenochova \& Havlicek, 2007), and physiological influences (Olsson et al., 2014; Shirasu \& Touhara, 2011; Singh \& Bronstad, 2001). However, research aimed at pinning down the most important chemical compounds shaping human chemosensory communication identified some crucial body odor components, namely, volatile steroids androstenol ( $5 \alpha$-androst-16-

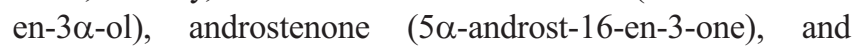
androstadienone (androsta-4,16-dien-3-one) and volatile fatty acids 3-hydroxy-3-methylhexanoic acid (HMHA) and 3-methyl-2-hexenoic acid (3M2H) (Gallagher et al., 2008; Natsch et al., 2006; Natsch \& Emter, 2020; Zhou et al., 2014). A number of studies indicate possible chemosignaling functions of volatile steroids, showing their influence on the autonomic nervous system and on psychological and physiological reactions of other individuals (for a review see Havlicek et al., 2010). However, given that sociosexual experimental context possibly moderates the 16-androstenes' effects (Jacob et al., 2001; Lundström \& Olsson, 2005), current research has begun to analyze more thoroughly the social meaning of volatile fatty acids that significantly contribute to axillary odor (Natsch et al., 2006; Troccaz et al., 2009). HMHA seems to be particularly interesting in this context; as this acid is human-specific and has been detected in all individuals (Natsch \& Emter, 2020), it is quantitatively the most dominant human odorant (Natsch et al., 2003), and its assessments were shown to be independent of culture or sex (Ferdenzi et al., 2019). Although the genetic basis of body odor perception has not been reported so far (Natsch \& Emter, 2020), it has recently been discovered that among six receptors involved in the perception of sweat carboxylic acids, one receptor seems to be selectively responding to HMHA and no other acid (Chatelain \& Veithen, 2016). Combined, these special qualities of HMHA substance make it particularly relevant to investigate social consequences of body odor perception or body odor anosmias.

It is crucial to note here that studies report a significant proportion of people suffering from a specific anosmia to body odor-relevant substances (Bremner et al., 2003; Ferdenzi et al., 2019; Hummel et al., 2005). This means that a large proportion of the population cannot perceive these odors, whereas their sensitivity to other substances remains unaffected. For example, the frequency of specific anosmia to HMHA ranges between $8 \%$ and 19\% (Ferdenzi et al., 2019), and based on the patent of Chatelain and Veithen (2016) reported by Natsch and Emter (2020), we may assume that this anosmia can be genetically/biologically determined. The undeniable scale of this problem, and the fact that anosmia to certain crucial components of body odor may be present in the lives of many individuals from birth onward, opens new questions regarding the social consequences of anosmias to body odor components. This research avenue has not been explored much so far. We know that people able to perceive volatile steroids are more likely to reject others based on body odors as compared with people with specific anosmia (Pierce et al., 2004), and that decreased detection accuracy, confidence, and intensity ratings for androstenone predict higher defensiveness (Kline et al., 2007). No study has assessed the social effects of anosmia to fatty acids.

Another issue related to social consequences of olfactory abilities is that certain groups of people can be particularly sensitive to the psychological effects of body odors or their impaired reception. Blind people declare being more conscious of socially relevant smells than sighted individuals (Beaulieu-Lefebvre et al., 2011). Even in childhood, blindness is associated with higher awareness of odors, particularly in the social domain (Ferdenzi et al., 2010). Although a recent meta-analysis indicated no significant differences in olfactory sensitivity of people with and without blindness (Sorokowska et al., 2019) and blind people do not exhibit an enhanced conscious understanding of social information conveyed by body odors (Sorokowska \& Oleszkiewicz, 2019), blindness was found to relate to a better recognition of negative emotions in odor cues (Iversen et al., 2015). It can therefore be assumed that blind people exhibit certain advantages in processing of the social information based on body odors. Consequently, sensitivity to socially relevant olfactory cues can make blind people more subject to the detrimental effects of anosmia to body odor-related substances or their distorted perception.

In summary, body odors convey information about people and exhibit many effects on social functioning of an individual. Perception of HMHA, a compound that significantly influences human body odor, could also be linked to this research area. However, no study so far has addressed the problem of HMHA perception in the context of the previously reported relationship between olfactory abilities and social difficulties. Guided by previous research (Desiato et al., 2020; Sivam et al., 2016), we focused on loneliness in both the social and emotional context, and understood both as a subjective, cognitive evaluation of social participation and one's social isolation (de Jong Gierveld \& Van Tilburg, 2010). As people with blindness report an increased focus on socially relevant odor information, we have also separately analyzed, in this research, the effects and correlates of HMHA perception in relation to blindness.

\section{Materials and Methods}

\section{Ethical Approval}

The study was conducted in accordance with the Helsinki Declaration and data collection complied with current American Psychological Association's (APA) Ethical Principles of Psychologists and Code of Conduct. The project was accepted by the ethical board of the relevant institution, 
and all subjects provided a written, informed consent prior to study inclusion (the form was read aloud to the subjects with visual impairment). The participants were informed that their participation is entirely voluntary and that they can withdraw their consent at any moment. They received a monetary remuneration for their participation in a series of scientific studies unrelated to the presented research.

\section{Participants}

The required sample size was calculated with $\mathrm{G}^{*}$ Power software (Faul et al., 2007). To reach the power of $1-\beta=.90$ within the analysis of variance $d f 1=1$ and a single covariate, with the level of significance set to $\alpha=.05$ to detect medium-sized effects $f=.25$, the sample was estimated as at least 175 subjects. The study comprised 196 people aged between 17 and 57 years $\left(M_{\text {age }}=34.07, S D_{\text {age }}=10.34\right.$ years), of whom 99 were blind (46 females; $M_{\text {age }}=36.48$, $S D_{\text {age }}=10.04$ years) and 97 were sighted (51 females; $M_{\text {age }}$ $=31.61, S D_{\text {age }}=10.11$ years $)$. The participants were recruited by means of advertisements in local media, in local associations and schools for people with blindness, and by means of personal contacts of the participants and the experimenters. The participants reported no neurological or olfactory disorders.

\section{Materials}

Odor sample. We used $0.01 \%$ solution (v/v) of racemic 3-hydroxy-3-methylhexanoic acid of $>99 \%$ GC purity (HMHA; Chemical Abstracts Service [CAS] number: 5888876-9) in odorless mineral oil. The applied supraliminal HMHA concentration was determined on the basis of previous research in an European sample (Ferdenzi et al., 2019), where an average detection threshold was $12.5 \times 10^{-6}$. HMHA was synthesized by one of the authors (N.B.) for the purpose of the study, using procedures adapted from published protocols (Ferdenzi et al., 2019). The sample $-4.5 \mathrm{~mL}$ of the target odorant - was presented in a $15-\mathrm{mL}$ amber glass flask that was about $7 \mathrm{~cm}$ high ( $3 \mathrm{~cm}$ in diameter).

Loneliness. Loneliness in this research was understood both in the social and in the emotional context, and as a subjective, cognitive evaluation of one's social participation and one's social isolation. Therefore, we operationalized this construct in two ways-hereafter referred to as social and emotional "loneliness" and as "social withdrawal." Self-assessed "loneliness" was measured with the use of the 11-item De Jong Gierveld Loneliness Scale (de Jong-Gierveld \& Kamphuls, 1985) in a Polish adaptation by Grygiel and collaborators (2013). The De Jong Gierveld Loneliness Scale is an established method with good psychometric qualities $(\alpha=.89$ in the Polish adaptation). The scale contains two subscalesemotional and social loneliness - and generally assesses the satisfaction from the size, composition, and quality of one's social relationships (e.g., I miss the company of other people; I can count on my friends in the times of need). The participants assessed the level of agreement with each statement on a 1 to 7 scale, from definitely yes to definitely no. Scoring of a few items is reversed so that in the final results higher scores reflect higher loneliness. Social withdrawal was measured with a Social Withdrawal Subscale derived from Comprehensive Assessment of Traits Relevant to Personality DisorderStatic Form Scale (CAT-PD-SF) v1.1 (Simms et al., 2011): https://ipip.ori.org/newCAT-PD-SFv1.1Keys.htm. This sixitem scale was found to have satisfactory psychometric qualities in both a general community and patient samples (six items; Comm. $\alpha=.83$, Pat. $\alpha=.87$ ). The full questionnaire and its English translation can be found at https://osf.io/ hwxc7/?view_only=ae372df9972a443ea3c082f17b5afaf6 (See also Supplemental Materials).

\section{Procedure}

The study was conducted by trained research assistants at the university and at a local school for individuals with blindness. Every person was tested individually, and throughout testing, the participants without visual impairment were additionally asked to wear a mask that covered their eyes without blocking their noses (Mindfold; Mindfold Inc., Colorado, USA).

Odor perception. The participants were explained that they will be asked to smell a sample of an odor, and if they perceived it they would be additionally asked three questions about this odor. They were also instructed to inhale deeply when being told so. The experimenters presented an odor sample for approximately $3 \mathrm{~s}$, moving an open flask below the subject's nostrils. The subjects were then asked whether they perceived any odor (yes/no). The individuals who declared that they did not perceive any odor were informed that they should not worry, as anosmia to this particular substance is quite common. They were further classified as "specific anosmia" for the purpose of further analyses. The individuals who did perceive the odor were asked to assess the qualities of the odor on three scales: (a) pleasantness, with response ranging from -5 (very unpleasant) to 5 (very pleasant); (b) intensity, with response ranging from 0 (not intense at all) to 10 (very intense); and (c) familiarity, with response ranging from 0 (not familiar at all) to 10 (very familiar). The odor was presented to the participants prior to each of the three questions.

Questionnaire assessment. To standardize study conditions across the experimental groups, the research assistants read the demographic questions and the questionnaires aloud to people with and without visual impairment and marked their responses on the answer sheets.

Statistical analyses. We have first assessed the independence of HMHA-specific anosmia from blindness with $\chi^{2}$ 
Table I. Self-Assessed Loneliness and Social Withdrawal in Relation to Sightedness and HMHA Anosmia.

\begin{tabular}{|c|c|c|c|c|c|c|c|c|}
\hline \multirow[b]{3}{*}{ Dependent variables } & \multicolumn{4}{|c|}{ Subjects with blindness } & \multicolumn{4}{|c|}{ Subjects without blindness } \\
\hline & \multicolumn{2}{|c|}{ Anosmia $(n=18)$} & \multicolumn{2}{|c|}{ No anosmia $(n=8 \mathrm{I})$} & \multicolumn{2}{|c|}{ Anosmia $(n=15)$} & \multicolumn{2}{|c|}{ No anosmia $(n=82)$} \\
\hline & $M$ & $S D$ & $M$ & $S D$ & $M$ & $S D$ & $M$ & $S D$ \\
\hline Social withdrawal & 2.73 & 0.59 & 2.92 & 0.87 & 2.79 & 0.92 & 2.98 & 0.83 \\
\hline General loneliness & 3.37 & 0.54 & 3.36 & 0.58 & 3.06 & 0.52 & 3.16 & 0.48 \\
\hline Social loneliness & 2.60 & 0.95 & 3.03 & 1.25 & 2.48 & 0.81 & 2.67 & 1.20 \\
\hline Emotional loneliness & 2.71 & 1.30 & 2.59 & 1.26 & 1.99 & 1.22 & 2.19 & 1.09 \\
\hline
\end{tabular}

Note. HMHA = 3-hydroxy-3-methyl-hexanoic acid.

distribution. Furthermore, we computed the general linear models to assess potential differences in loneliness and social withdrawal in people in relation to the specific anosmia to HMHA (with vs. without), taking into account also the visual impairment of the subjects (with vs. without) and controlling for their age. The models were computed separately for loneliness (and the subscales: social and emotional loneliness) and social withdrawal. Finally, we correlated the psychophysiological assessments of HMHA samples (pleasantness, intensity, and familiarity) with loneliness and social withdrawal scores. Based on the results of general linear models, we decided to assess the correlations separately for blind and sighted subjects. All data for this study are available at https://osf.io/hwxc7/?view_only=ae372df9972a443ea3c082 f17b5afaf6.

\section{Results}

\section{Effects of HMHA-Specific Anosmia}

HMHA-specific anosmia was independent from blindness, $\chi^{2}(1)=.26, p=.61$ (for frequencies, see Table 1). Descriptive statistics for the self-assessed loneliness (in distinction to social and emotional loneliness) and social withdrawal in subjects with and without blindness who exhibited versus did not exhibit specific anosmia to HMHA are summarized in Table 1.

Overall, we observed specific anosmia to HMHA in 33 individuals (18 blind and 15 sighted individuals). Subjects with blindness declared higher general loneliness than subjects without blindness: 3.36 vs. 3.14 points; $F(1,192)=$ 4.99, $p=.027, \eta^{2}=.03,95 \%$ confidence interval $(\mathrm{CI})=$ $[.03, .43]$. Neither the HMHA anosmia nor the interaction of sightedness and HMHA anosmia proved to have a significant effect on the self-assessed general loneliness. We found that the effect of blindness observed for the general loneliness was driven by the scores in the emotional loneliness subscale, $F(1,192)=4.72, p=.031, \eta^{2}=.0395 \% \mathrm{CI}=[.05$, $.95]$, wherein subjects with blindness declared significantly higher emotional loneliness than subjects without blindness (2.61 vs. 2.11 points, respectively). The analogous model examining the effects of blindness and HMHA-specific anosmia on the social loneliness subscale yielded no significant results. Moreover, there were no significant effects for the model examining the variability in social withdrawal as a function of blindness and HMHA-specific anosmia. The main effect of blindness on emotional loneliness (reflected also in the general loneliness scale) is illustrated in Figure 1.

\section{Psychophysical Assessments of HMHA}

The perception of HMHA pleasantness was positively associated with social withdrawal of the subjects with blindness $(r=.29, p=.007)$ but not in sighted subjects $(p=.50)$. Neither social nor emotional loneliness was positively associated with the hedonic perception of HMHA in the two groups. There were no significant relationships between ratings of intensity of HMHA, loneliness, or social withdrawal (all $p \mathrm{~s}>.05$ ). Finally, regardless of sightedness, in both groups there was a significant correlation between emotional loneliness and familiarity of HMHA $\left(r_{\text {sighted }}=.28, p=.01\right.$; $\left.r_{\text {blind }}=.26, p=.02\right)$. The scatterplot matrix for intercorrelations between the psychophysiological ratings of HMHA, self-assessed loneliness, and social withdrawal is presented in Figure 2.

\section{Discussion}

Olfactory sensitivity often relates to social problems and, in this study, we assessed whether the perception of a crucial component of human body odor (HMHA) is significantly associated with loneliness. We assumed that the effects could be particularly salient among people with blindness, who were shown to pay a special attention to odor cues in the social context. Overall, the results we observed were quite inconsistent with our predictions. Neither the HMHA anosmia nor the interaction of sightedness and HMHA anosmia proved to have a significant effect on the self-assessed loneliness or social withdrawal. As for the psychophysical ratings of HMHA within the group of individuals who could smell this substance, the study yielded mixed findings that depended on sightedness of the subjects. HMHA familiarity was positively related to emotional loneliness, regardless of the sightedness status, but pleasantness of HMHA samples 


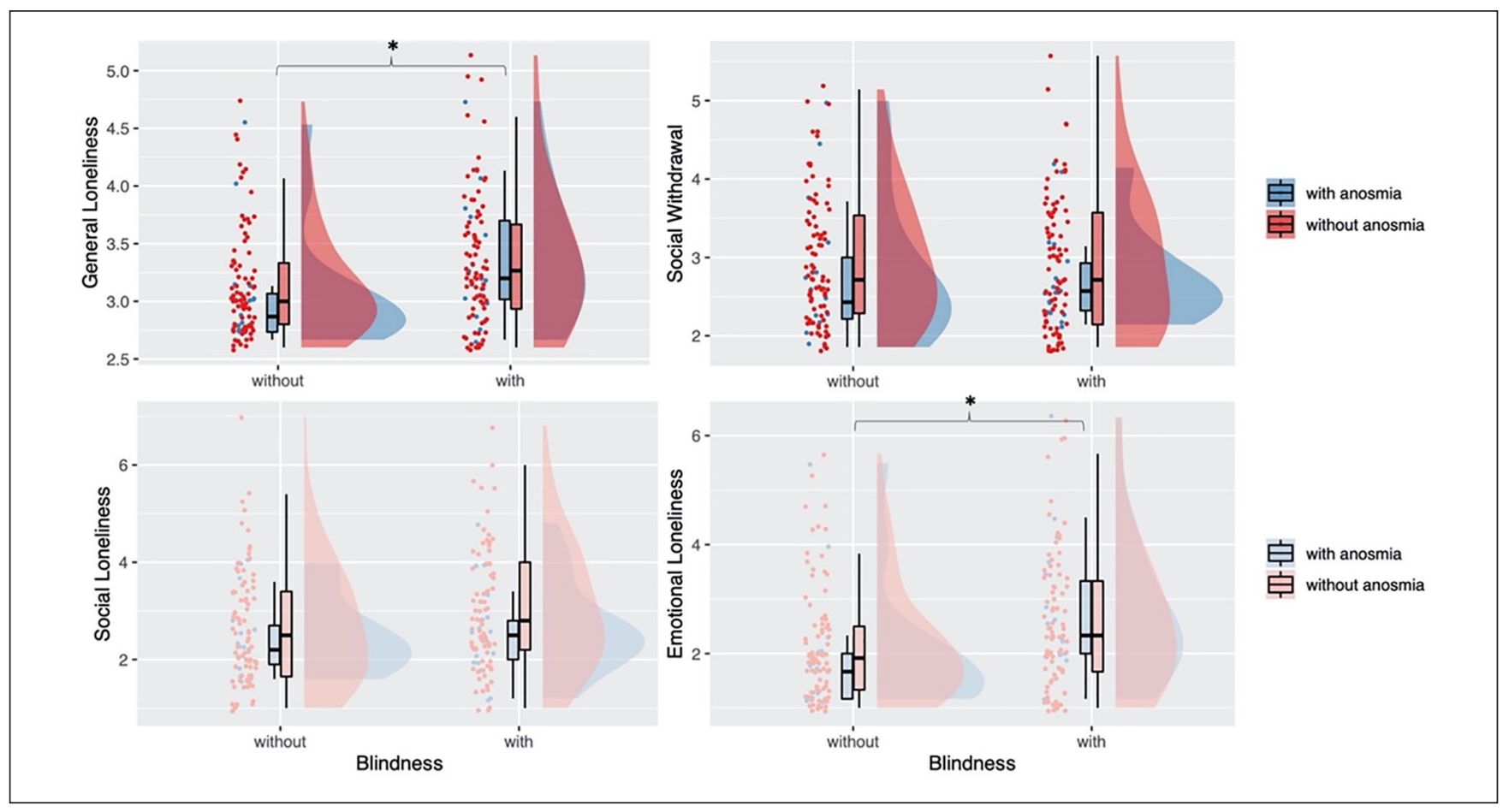

Figure I. Distribution of loneliness and social withdrawal scores in subjects with and without blindness, with and without HMHAspecific anosmia.

Note. Bars indicate $95 \%$ confidence intervals. HMHA = 3-hydroxy-3-methylhexanoic acid. $* p=.027$.

was positively related to social withdrawal scores only for people with blindness.

The first and most important result of our study was that HMHA anosmia was not a significant predictor of loneliness across our samples and that we observed no interactive effect of sightedness and HMHA anosmia on the assessed scales. Lack of this effect was not consistent with our expectations. Previous research has documented detrimental effects of general olfactory impairments on human social life (Croy et al., 2013; Desiato et al., 2020; Sivam et al., 2016). We may thus only speculate as to why anosmia to an important body odor component does not predict a lower self-assessed loneliness.

The first hypothesis relates to the body odor proxy we selected. "Real" body odor samples are complex mixtures consisting of many molecules, and they contain several important odorous substances (Natsch \& Emter, 2020). They can also be affected by numerous processes, changes, and characteristics of odor donors. In this study, we decided to apply an artificial, chemical substance that was shown to strongly remind people of real body odors in previous research (Ferdenzi et al., 2019) and is the most dominant compound of the human body odor (Natsch et al., 2003). Therefore, the social consequences of anosmia to this substance should, theoretically, be the most likely to be observed. Nevertheless, HMHA is just one of a few body odor components (Gallagher et al., 2008; Troccaz et al., 2009), and anosmia to this substance does not entirely disable perception of socially relevant olfactory cues. Ferdenzi and collaborators (2019) showed that few participants exhibited specific anosmias to several substances out of the four different body odor compounds they used in their research, and only one participant out of 40 was anosmic to both HMHA and 3HMA. To explore this issue more thoroughly, future studies on body odor perception and loneliness should involve the assessment of anosmias to several suprathreshold body odor components, preferably combined with real body odor samples.

Second, altered or weakened perception of HMHA may relate to social difficulties other than loneliness. Selfassessment of loneliness is complex and very subjective (McAdam, 2016) and it can relate to environmental and personal factors that were not controlled in this study. For example, people anosmic to HMHA (or to other body odor components) can become particularly proactive in searching for and sensitive to other social cues, allowing for a compensatory effect on one's social interactions and decreasing any possible difference between them and HMHA-perceiving individuals. Overall, it is still possible that other areas of everyday social interactions are affected by HMHA-specific anosmia, or that loneliness is affected by anosmia to other body odor components. To determine whether any of our hypotheses is probable, it would be necessary to conduct more extensive studies that would involve a broader range of odorants, measurement of other socially relevant personality traits and behaviors, and that would compare sensitivity to social cues pertaining to different modalities. 


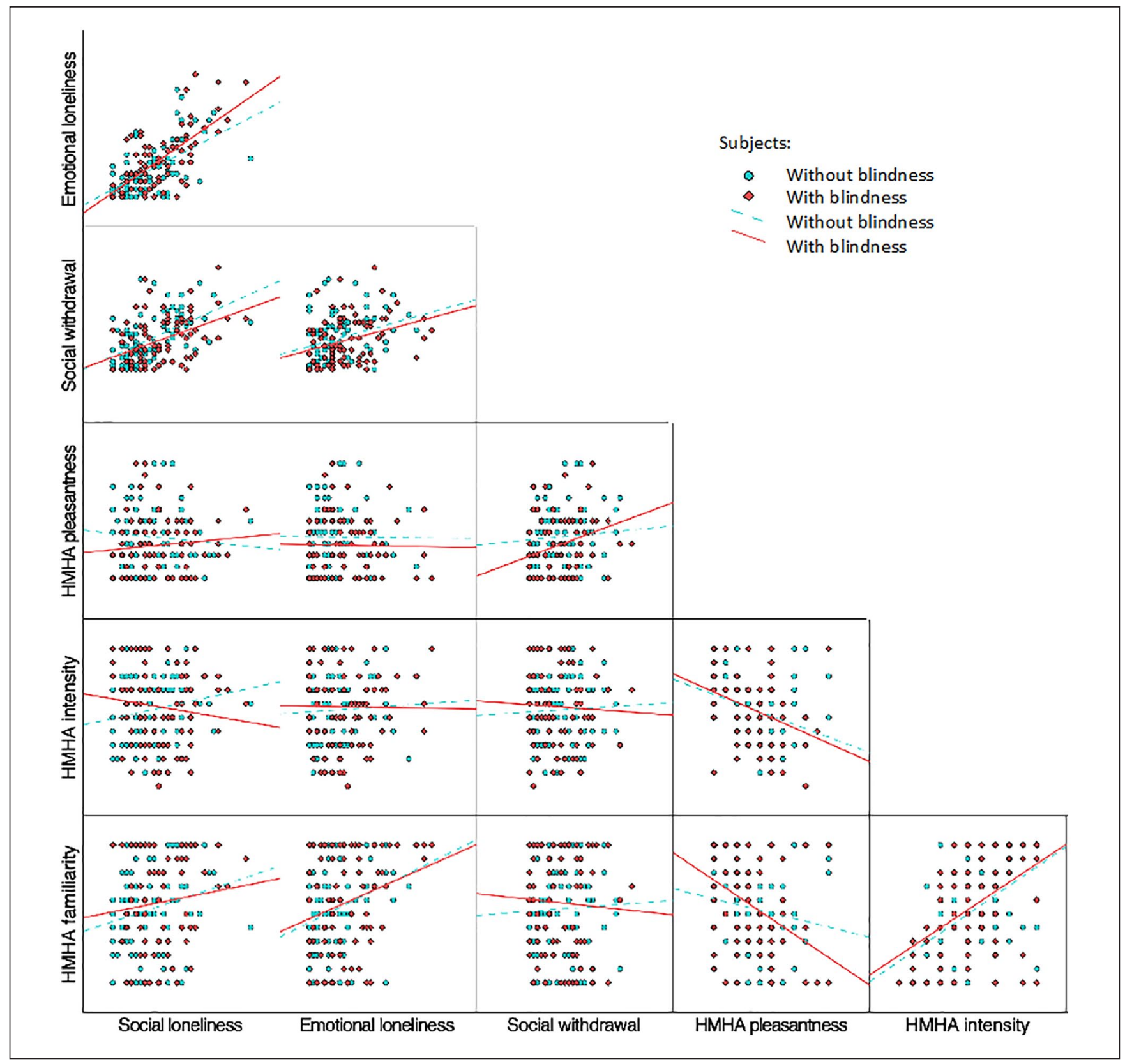

Figure 2. The scatterplot matrix for intercorrelations between the psychophysiological ratings of HMHA, self-assessed loneliness, and social withdrawal across subjects with and without blindness. Note. HMHA = 3-hydroxy-3-methylhexanoic acid.

Interestingly, different aspects of loneliness were found to positively correlate with assessments of HMHA pleasantness and familiarity by individuals who were able to detect this substance. This volatile fatty acid might therefore activate a "social longing" schema, wherein smelling it triggers thinking about others, missing their proximity, and higher loneliness. In this case, smelling a body odor proxy would enhance social needs, consequently driving social cohesion. This mechanism would be consistent with the assumed bonding role of body odors in mother-child interactions throughout the early stages of a human life (Croy et al., 2019; Porter et al., 1983; Schäfer et al., 2020). However, quite an opposite mechanism may also be true. Natural body odors are generally perceived as unpleasant in Western cultures (Schleidt et al., 1981) and previous research showed that negative perception of body odors evokes spontaneous associations with negative personality traits (McBurney et al., 1976; Sorokowska, 2013) and may lead to more frequent rejection of others based on smell (Pierce et al., 2004). In this case, unpleasant sensations associated with olfactory perception of 
others could consequently decrease the overall sociability and longing for social contacts.

It might be questioned whether the - seemingly unrelated to the loneliness concept-perception of a body odor compound might drive altered responses in loneliness questionnaires. However, the effects of body odor-related odorants on social behavior are quite potent, as indicated by numerous studies on their pronounced psychological effects (de Groot et al., 2017). For example, Chen and Haviland-Jones (1999) reported that following an assessment of an elderly woman's body odor, people reported reduced feelings of depressed affect on the mood-assessment questionnaire. Fear-related human chemosignals were, in turn, found to significantly impact state-trait anxiety inventory scores in females (Albrecht et al., 2011) and to translate to several psychological effects, such as increased risk-taking (Haegler et al., 2010), higher stress and mistrust toward an unknown man encountered within a virtual environment (Quintana et al., 2019), or detection of fear while recognizing ambiguous facial expression (Zhou \& Chen, 2009). Adding the outcomes of our study to this large body of literature and knowing the quite reliable interaction between certain aspects of social functioning and olfactory sensitivity in previous research (Desiato et al., 2020; Sivam et al., 2016), we suggest that it is of great interest to further investigate the behavioral, psychological, and physiological effects of body odor perception.

We assumed that all effects predicted in this study can be more salient for people with visual impairment. Sighted people can rely on a number of sources of social information, with visual data easily supplementing the olfactory social cues. People with blindness, at the same time, are more aware of social olfactory information and were shown to be particularly sensitive to emotional odor cues (Iversen et al., 2015) and pay high attention to such data (Beaulieu-Lefebvre et al., 2011). Interestingly, however, in our study, emotional loneliness significantly correlated with HMHA odor familiarity in both the sighted and the blind subjects. In the sample with blindness, the pleasantness assessments were, moreover, positively and significantly related to social withdrawal. One reason why we observed this mixed pattern of findings is that the three included loneliness measures tap onto different aspects of loneliness, moderating their association with olfaction (similar to Desiato et al., 2020). The social and emotional loneliness subscales relate to the cognitive evaluation of social participation (de Jong Gierveld \& Van Tilburg, 2010). For example, the social loneliness is linked primarily to the perceived qualities of one's broader network of relationships, including its size and composition. Social withdrawal included in our research pertains mostly to the feeling of a general isolation (Simms et al., 2011). At this stage of research, it remains unknown, however, why body odor perception relates to different aspects of loneliness in the sighted and in the blind people.

It should be also noted that the blind individuals declared higher general loneliness than sighted subjects in our sample.
This result concurs with the previously observed association between physical health and loneliness (Korporaal et al., 2008; Penninx et al., 1999; Savikko et al., 2005). This study extends our understanding of the relationship between sightedness and social functioning, stating that even poor vision can accelerate loneliness in older age (Savikko et al., 2005) by showing that this also applies to adults with blindness. Despite these negative effects, people with blindness exhibit similar (Oleszkiewicz et al., 2017) or even a higher level of interpersonal trust than sighted people (Oleszkiewicz, 2021), proving that visual impairment may have negative consequences on the particular aspects of social relationships of people with blindness, but still allow them to build positive social attitudes in other domains.

There are certain limitations of this research. First, the "yes/no" response format could have affected our findings on HMHA anosmia and loneliness. It would be more recommendable to apply a more robust method to assess anosmia to HMHA, such as a two- or three-alternate forced-choice procedure involving odorant and blank(s) and a forced choice on which of the flasks contains the odorant. Unfortunately, our "yes/no" procedure in anosmia assessment could have resulted in a response bias through applying either lenient criteria for deciding there is an odor present versus overly cautious criteria (only stating there is an odor if it is of $100 \%$ certainty). Some HMHA anosmics could have, therefore, been undetected in our sample, and some anosmics could have also attempted to perform the psychophysical ratings of the sample. Nevertheless, we may argue that the impact of this testing method on our particular study is largely mitigated by several important issues. First, our subjects were aware that after being presented with a certain odor, they will be asked to rate it using provided scales. Including the consecutive intensity assessment also means that we had two methods of analysis, allowing us to verify whether the subjects perceived this odor. Among 163 subjects who declared smelling HMHA, only one person described the odor intensity as "0." Second, the issue of odor perception has no positive or negative connotations, which could make this response less prone to a self-presentation bias. Third, the HMHA sample itself allows us to suggest that the responses we collected were rather reliable. Overall, people exhibit a very low detection threshold for this substance (Ferdenzi et al., 2019; Natsch \& Emter, 2020), and the concentration we chose for our study was high enough to be reliably detected by people sensitive to HMHA. This further decreases a risk of uncertainty when being asked to decide whether one can perceive an odor or not. Finally, $16.8 \%$ of anosmic subjects in our sample is consistent with the range between $8 \%$ and 19\% reported by Ferdenzi et al. (2019) and around 20\% as mentioned by Natsch and Emter (2020).

We may also presume that certain aspects of the experimental situation could have influenced our findings. Situational context was shown to affect the psychophysiological reactions to 16-androstenes (Havlicek et al., 2010; 
Personality and Social Psychology Bulletin 00(0)

Jacob et al., 2001; Lundström \& Olsson, 2005; Verhaeghe et al., 2013). Several experimental studies showed a crucial role of the experimenter's sex in the observed results. This factor seems to be particularly important for female participants interacting with male experimenters (Jacob et al., 2001; Lundström \& Olsson, 2005). It has been speculated that the psychophysiological effects of volatile body odor components may be particularly salient in the presence of a male [experimenter]. However, previous studies on the mating context and social interactions with opposite sex focused almost exclusively on 16 -androstenes. It is difficult to predict whether the experimenter's sex effect might have affected our outcomes, given that this study's majority research assistants were female. We should also remember that body odors are now often modified and masked by cosmetics and fragrances, which can distort the socially relevant signaling odor properties (Sorokowska et al., 2016). It is not fully clear whether the associations between psychophysical odor assessments and different aspects of loneliness would be replicated with the body odor samples that are subject to the influence of chemical alterations.

Human olfaction literature and psychological studies document a significant relationship between body odors and social communication. In this study, we did not find support for the hypothesis that HMHA-specific anosmia leads to social loneliness, yet we found people with blindness to be indeed more lonely than sighted people. Among those who could smell HMHA body odor compound, HMHA familiarity was linked to emotional loneliness regardless of sightedness, but pleasantness of HMHA samples was positively related to social withdrawal scores only for people with blindness.

\section{Declaration of Conflicting Interests}

The author(s) declared no potential conflicts of interest with respect to the research, authorship, and/or publication of this article.

\section{Funding}

The author(s) disclosed receipt of the following financial support for the research, authorship, and/or publication of this article: This work was supported by the Polish Ministry of Science and Higher Education scholarship for the years 2018-2020 (No. 626/ STYP/12/2017) and the Polish National Science Centre OPUS Grant (No. 2017/25/B/HS6/00561), both awarded to A.O.

\section{ORCID iD}

Agnieszka Sorokowska iD https://orcid.org/0000-0003-3999-8851

\section{Supplemental Material}

Supplemental material is available online with this article.

\section{References}

Albrecht, J., Demmel, M., Schopf, V., Kleemann, A. M., Kopietz, R., May, J., Schreder, T., Zernecke, R., Bruckmann, H., \&
Wiesmann, M. (2011). Smelling chemosensory signals of males in anxious versus nonanxious condition increases state anxiety of female subjects. Chemical Senses, 36(1), 19-27. https://doi.org/10.1093/chemse/bjq087

Beaulieu-Lefebvre, M., Schneider, F. C., Kupers, R., \& Ptito, M. (2011). Odor perception and odor awareness in congenital blindness. Brain Research Bulletin, 84(3), 206-209. https:// doi.org/10.1016/j.brainresbull.2010.12.014

Boesveldt, S., Yee, J. R., McClintock, M. K., \& Lundström, J. N. (2017). Olfactory function and the social lives of older adults: A matter of sex. Scientific Reports, 7, Article 45118. https:// doi.org/10.1038/srep45118

Bremner, E. A., Mainland, J. D., Khan, R. M., \& Sobel, N. (2003). The prevalence of androstenone anosmia. Chemical Senses, 28(5), 423-432. https://doi.org/10.1093/chemse/28.5.423

Chatelain, P., \& Veithen, A. (2016). Olfactory receptors involved in the perception of sweat carboxylic acids and the use thereof (Patent No. EP3004157B1). European Patent Application.

Chen, D., \& Haviland-Jones, J. (1999). Rapid mood change and human odors. Physiology \& Behavior, 68(1-2), 241-250. https://doi.org/10.1016/S0031-9384(99)00147-X

Chen, D., \& Haviland-Jones, J. (2011). Human olfactory communication of emotion. Perceptual and Motor Skills, 91(3), 771-781. https://doi.org/10.2466/pms.2000.91.3.771

Croy, I., Bojanowski, V., \& Hummel, T. (2013). Men without a sense of smell exhibit a strongly reduced number of sexual relationships, women exhibit reduced partnership security-A reanalysis of previously published data. Biological Psychology, 92(2), 292-294. https://doi.org/10.1016/j.biopsycho.2012.11.008

Croy, I., Mohr, T., Weidner, K., Hummel, T., \& Junge-Hoffmeister, J. (2019). Mother-child bonding is associated with the maternal perception of the child's body odor. Physiology \& Behavior, 198, 151-157. https://doi.org/10.1016/J.PHYSBEH.2018.09.014

Croy, I., Negoias, S., Novakova, L., Landis, B. N., \& Hummel, T. (2012). Learning about the functions of the olfactory system from people without a sense of smell. PLOS ONE, 7(3), Article e33365. https://doi.org/10.1371/journal.pone.0033365

de Groot, J. H. B., Semin, G. R., \& Smeets, M. A. M. (2017). On the communicative function of body odors. Perspectives on Psychological Science, 12(2), 306-324. https://doi.org $/ 10.1177 / 1745691616676599$

de Jong-Gierveld, J., \& Kamphuls, F. (1985). The development of a Rasch-Type Loneliness Scale. Applied Psychological Measurement, 9(3), 289-299. https://doi.org/10.1177/014662 168500900307

de Jong Gierveld, J., \& Van Tilburg, T. (2010). The De Jong Gierveld short scales for emotional and social loneliness: Tested on data from 7 countries in the UN generations and gender surveys. European Journal of Ageing, 7(2), 121-130. https://doi.org/10.1007/s10433-010-0144-6

Desiato, V. M., Soler, Z. M., Nguyen, S. A., Salvador, C., Hill, J. B., Lamira, J., Rowan, N. R., Yoo, F., Little, R. E., Matthews, L. J., Dubno, J. R., \& Schlosser, R. J. (2020). Evaluating the relationship between olfactory function and loneliness in community-dwelling individuals: A cross-sectional study. American Journal of Rhinology \& Allergy, 35(3), 334-340. https://doi. org/10.1177/1945892420958365

Faul, F., Erdfelder, E., Lang, A.-G., \& Buchner, A. (2007). G*Power 3: A flexible statistical power analysis program 
for the social, behavioral, and biomedical sciences. Behavior Research Methods, 39(2), 175-191. https://doi.org/10.3758/ BF03193146

Ferdenzi, C., Coureaud, G., Camos, V., \& Schaal, B. (2010). Attitudes toward everyday odors for children with visual impairments: A pilot study. Journal of Visual Impairment \& Blindness, 104, 55-60.

Ferdenzi, C., Razafindrazaka, H., Baldovini, N., Poupon, D., Pierron, D., \& Bensafi, M. (2019). Influence of gender and culture on the perception of acidic compounds of human body odor. Physiology and Behavior, 210, Article 112561. https:// doi.org/10.1016/j.physbeh.2019.112561

Fialová, J., Roberts, S. C., \& Havlíček, J. (2013). Is the perception of dietary odour cues linked to sexual selection in humans? In M. East \& M. Dehnhard (Eds.), Chemical signals in vertebrates 12 (pp. 161-169). Springer. https://doi.org/10.1007/978-14614-5927-9 12

Fialová, J., Roberts, S. C., \& Havlíček, J. (2016). Consumption of garlic positively affects hedonic perception of axillary body odour. Appetite, 97, 8-15. https://doi.org/10.1016/j.appet.2015.11.001

Gallagher, M., Wysocki, C. J., Leyden, J. J., Spielman, A. I., Sun, X., \& Preti, G. (2008). Analyses of volatile organic compounds from human skin. British Journal of Dermatology, 159(4), 780-791. https://doi.org/10.1111/j.1365-2133.2008.08748.x

Grygiel, P., Humenny, G., Rebisz, S., Świtaj, P., \& Sikorska, J. (2013). Validating the Polish adaptation of the 11-item De Jong Gierveld Loneliness Scale. European Journal of Psychological Assessment, 29(2), 129-139. https://doi.org/10.1027/10155759/a000130

Haegler, K., Zernecke, R., Kleemann, A. M., Albrecht, J., Pollatos, O., Brückmann, H., \& Wiesmann, M. (2010). No fear no risk! Human risk behavior is affected by chemosensory anxiety signals. Neuropsychologia, 48(13), 3901-3908. https://doi. org/10.1016/j.neuropsychologia.2010.09.019

Havlicek, J., Murray, A. K., Saxton, T. K., \& Roberts, S. C. (2010). Current issues in the study of androstenes in human chemosignaling. Vitamins and Hormones, 83, 47-81. https://doi. org/10.1016/S0083-6729(10)83003-1

Havlicek, J., \& Roberts, S. C. (2009). MHC-correlated mate choice in humans: A review. Psychoneuroendocrinology, 34(4), 497-512. https://doi.org/10.1016/j.psyneuen.2008.10.007

Hummel, T., Krone, F., Lundström, J. N., \& Bartsch, O. (2005). Androstadienone odor thresholds in adolescents. Hormones and Behavior, 47(3), 306-310. https://doi.org/10.1016/j. yhbeh.2004.10.007

Iversen, K. D., Ptito, M., Møller, P., \& Kupers, R. (2015). Enhanced chemosensory detection of negative emotions in congenital blindness. Neural Plasticity, 2015, Article 469750. https://doi. org/10.1155/2015/469750

Jacob, S., Hayreh, D. J. S., \& McClintock, M. K. (2001). Contextdependent effects of steroid chemosignals on human physiology and mood. Physiology and Behavior, 74(1-2), 15-27. https://doi.org/10.1016/S0031-9384(01)00537-6

Kline, J. P., Schwartz, G. E., \& Dikman, Z. V. (2007). Interpersonal defensiveness and diminished perceptual acuity for the odor of a putative pheromone: Androstenone. Biological Psychology, 74(3), 405-413. https://doi.org/10.1016/J.BIOPSYCHO.2006.10.003

Korporaal, M., Broese Van Groenou, M. I., \& Van Tilburg, T. G. (2008). Effects of own and spousal disability on loneliness among older adults. Journal of Aging and Health, 20(3), 306-325. https://doi.org/10.1177/0898264308315431

Lenochova, P., \& Havlicek, J. (2007). Human body odour individuality. In J. L. Hurst, R. J. Beynon, S. C. Roberts, \& T. D. Wyatt (Eds.), Chemical signals in vertebrates 11 (pp. 189-198). Springer. https://doi.org/10.1007/978-0-387-73945-8_18

Lundström, J. N., \& Olsson, M. J. (2005). Subthreshold amounts of social odorant affect mood, but not behavior, in heterosexual women when tested by a male, but not a female, experimenter. Biological Psychology, 70(3), 197-204. https://doi. org/10.1016/j.biopsycho.2005.01.008

McAdam, D. J. (2016). Toward a social psychology of social movements. In J. A. Krosnick, I.-C. A. Chiang, \& T. H. Stark (Eds.), Political psychology: New explorations (pp. 98-121). Psychology Press. https://doi.org/10.4324/9781315445687

McBurney, D. H., Levine, J. M., \& Cavanaugh, P. H. (1976). Psychophysical and social ratings of human body odor. Personality and Social Psychology Bulletin, 3(1), 135-138. https://doi.org/10.1177/014616727600300126

Mitro, S., Gordon, A. R., Olsson, M. J., \& Lundström, J. N. (2012). The smell of age: Perception and discrimination of body odors of different ages. PLOS ONE, 7(5), Article e38110. https://doi. org/10.1371/JOURNAL.PONE.0038110

Natsch, A., Derrer, S., Flachsmann, F., \& Schmid, J. (2006). A broad diversity of volatile carboxylic acids, released by a bacterial aminoacylase from axilla secretions, as candidate molecules for the determination of human-body odor type. Chemistry \& Biodiversity, 3(1), 1-20. https://doi.org/10.1002/ cbdv.200690015

Natsch, A., \& Emter, R. (2020). The specific biochemistry of human axilla odour formation viewed in an evolutionary context. Philosophical Transactions of the Royal Society B: Biological Sciences, 375(1800), Article 20190269, https://doi. org/10.1098/rstb.2019.0269

Natsch, A., Gfeller, H., Gygax, P., Schmid, J., \& Acuna, G. (2003). A specific bacterial aminoacylase cleaves odorant precursors secreted in the human axilla. Journal of Biological Chemistry, 278(8), 5718-5727. https://doi.org/10.1074/jbc.M210142200

Oleszkiewicz, A. (2021). Blindness enhances interpersonal trust but deafness impedes social exchange balance. Personality and Individual Differences, 170, Article 110425. https://doi. org/10.1016/j.paid.2020.110425

Oleszkiewicz, A., Alizadeh, R., Altundag, A., Chen, B., Corrai, A., Fanari, R., Farhadi, M., Gupta, N., Habel, R., Hudson, R., Hughes, J. L., Joshi, A., Kamrava, S. K., Luckett, C., Mahmut, M. K., Masala, C., Mori, E., Pellegrino, R., Piras, R., . . . Hummel, T. (2020). Global study of variability in olfactory sensitivity. Behavioral Neuroscience, 134(5), 394-406. https:// doi.org/10.1037/bne0000378

Oleszkiewicz, A., Pisanski, K., \& Sorokowska, A. (2017). Does blindness influence trust? A comparative study on social trust among blind and sighted adults. Personality and Individual Differences, 111, 238-241. https://doi.org/10.1016/j.paid.2017.02.031

Olsson, M. J., Lundström, J. N., Kimball, B. A., Gordon, A. R., Karshikoff, B., Hosseini, N., Sorjonen, K., Olgart Höglund, C., Solares, C., Soop, A., Axelsson, J., \& Lekander, M. (2014). The scent of disease: Human body odor contains an early chemosensory cue of sickness. Psychological Science, 25(3), 817-823. https://doi.org/10.1177/0956797613515681 
Penninx, B. W. J. H., Van Tilburg, T., Kriegsman, D. W., Boeke, A. J. P., Deeg, D. J. H., \& Van Eijk, J. T. M. (1999). Social network, social support, and loneliness in older persons with different chronic diseases. Journal of Aging and Health, 11(2), 151-168. https://doi.org/10.1177/089826439901100202

Pierce, J. D., Cohen, A. B., \& Ulrich, P. M. (2004). Responsivity to Two odorants, androstenone and amyl acetate, and the affective impact of odors on interpersonal relationships. Journal of Comparative Psychology, 118(1), 14-19. https://doi.org /10.1037/0735-7036.118.1.14

Porter, R. H., Cernoch, J. M., \& McLaughlin, F. J. (1983). Maternal recognition of neonates through olfactory cues. Physiology \& Behavior, 30(1), 151-154. https://doi.org/10.1016/00319384(83)90051-3

Quintana, P., Nolet, K., Baus, O., \& Bouchard, S. (2019). The effect of exposure to fear-related body odorants on anxiety and interpersonal trust toward a virtual character. Chemical Senses, 44(9), 683-692. https://doi.org/10.1093/chemse/bjz063

Roberts, S. C., Gosling, L. M., Spector, T. D., Miller, P., Penn, D. J., \& Petrie, M. (2005). Body odor similarity in noncohabiting twins. Chemical Senses, 30(8), 651-656. https://doi. org/10.1093/chemse/bji058

Savikko, N., Routasalo, P., Tilvis, R. S., Strandberg, T. E., \& Pitkälä, K. H. (2005). Predictors and subjective causes of loneliness in an aged population. Archives of Gerontology and Geriatrics, 41(3), 223-233. https://doi.org/10.1016/j.archger .2005 .03 .002

Schäfer, L., Sorokowska, A., Sauter, J., Schmidt, A. H., \& Croy, I. (2020). Body odours as a chemosignal in the mother-child relationship: New insights based on an human leucocyte antigen-genotyped family cohort. Philosophical Transactions of the Royal Society B: Biological Sciences, 375(1800), Article 20190266. https://doi.org/10.1098/rstb.2019.0266

Schleidt, M., Hold, B., \& Attili, G. (1981). A cross-cultural study on the attitude towards personal odors. Journal of Chemical Ecology, 7(1), 19-31. https://doi.org/10.1007/BF00988632

Shirasu, M., \& Touhara, K. (2011). The scent of disease: Volatile organic compounds of the human body related to disease and disorder. Journal of Biochemistry, 150(3), 257-266. https:// doi.org/10.1093/jb/mvr090

Simms, L. J., Goldberg, L. R., Roberts, J. E., Watson, D., Welte, J., \& Rotterman, J. H. (2011). Computerized adaptive assessment of personality disorder: Introducing the CAT-PD project. Journal of Personality Assessment, 93, 380-389. https://ipip. ori.org/newCAT-PD-SFv1.1Keys.htm\#SocialWithdrawal

Singh, D., \& Bronstad, P. M. (2001). Female body odour is a potential cue to ovulation. Proceedings of the Royal Society B: Biological Sciences, 268(1469), 797-801. https://doi.org /10.1098/rspb.2001.1589

Sivam, A., Wroblewski, K. E., Alkorta-Aranburu, G., Barnes, L. L., Wilson, R. S., Bennett, D. A., \& Pinto, J. M. (2016). Olfactory dysfunction in older adults is associated with feelings of depression and loneliness. Chemical Senses, 41(4), 293-299. https://doi.org/10.1093/chemse/bjv088
Sorokowska, A. (2013). Seeing or smelling? Assessing personality on the basis of different stimuli. Personality and Individual Differences, 55(2), 175-179. https://doi.org/10.1016/j.paid. 2013.02 .026

Sorokowska, A., \& Oleszkiewicz, A. (2019). Body-odor based assessments of sex and personality-Non-significant differences between blind and sighted odor raters. Physiology and Behavior, 210, Article 112573. https://doi.org/10.1016/j.physbeh.2019.112573

Sorokowska, A., Sorokowski, P., \& Havlícek, J. (2016). Body odor based personality judgments: The effect of fragranced cosmetics. Frontiers in Psychology, 7, Article 530. https://doi. org/10.3389/fpsyg.2016.00530

Sorokowska, A., Sorokowski, P., Karwowski, M., Larsson, M., \& Hummel, T. (2019). Olfactory perception and blindness: A systematic review and meta-analysis. Psychological Research, 83(8), 1595-1611. https://doi.org/10.1007/s00426-018-1035-2

Sorokowska, A., Sorokowski, P., \& Szmajke, A. (2012). Does personality smell? Accuracy of personality assessments based on body odour. European Journal of Personality, 26(5), 496-503. https://doi.org/10.1002/per.848

Stefanczyk, M. M., \& Oleszkiewicz, A. (2020). It's not you, it's me-Disgust sensitivity towards body odor in deaf and blind individuals. Attention, Perception, and Psychophysics, 82(7), 3728-3736. https://doi.org/10.3758/s13414-020-02075-2

Stevenson, R. J. (2010). An initial evaluation of the functions of human olfaction. Chemical Senses, 35(1), 3-20. https://doi. org/10.1093/chemse/bjp083

Troccaz, M., Borchard, G., Vuilleumier, C., Raviot-Derrien, S., Niclass, Y., Beccucci, S., \& Starkenmann, C. (2009). Gender-specific differences between the concentrations of nonvolatile (R)/(S)-3-Methyl-3-Sulfanylhexan-1-Ol and (R)/ (S)-3-Hydroxy-3-Methyl-Hexanoic Acid odor precursors in axillary secretions. Chemical Senses, 34, 203-210. https://doi. org/10.1093/chemse/bjn076

Verhaeghe, J., Gheysen, R., \& Enzlin, P. (2013). Pheromones and their effect on women's mood and sexuality. Facts, Views \& Vision in ObGyn, 5(3), 189-195.

Wallace, P. (1977). Individual discrimination of humans by odor. Physiology and Behavior, 19(4), 577-579. https://doi. org/10.1016/0031-9384(77)90238-4

Zhou, W., \& Chen, D. (2009). Fear-related chemosignals modulate recognition of fear in ambiguous facial expressions. Psychological Science, 20(2), 177-183. https://doi.org/10.1111 /j.1467-9280.2009.02263.x

Zhou, W., Yang, X., Chen, K., Cai, P., He, S., \& Jiang, Y. (2014). Chemosensory communication of gender through two human steroids in a sexually dimorphic manner. Current Biology, 24(10), 1091-1095. https://doi.org/10.1016/j.cub.2014.03.035

Zou, L. Q., Yang, Z. Y., Wang, Y., Lui, S. S. Y., Chen, A. T., Cheung, E. F. C., \& Chan, R. C. K. (2016). What does the nose know? Olfactory function predicts social network size in human. Scientific Reports, 6(1), Article 25026. https://doi.org $/ 10.1038 /$ srep25026 